www.jmscr.igmpublication.org

Impact Factor 3.79

Index Copernicus Value: 5.88

ISSN (e)-2347-176x ISSN (p) 2455-0450

crossref DOI: _http://dx.doi.org/10.18535/jmscr/v4i02.16

Journal Of Medical Science And Clinical Research

\title{
Peripheral Neuropathy In Rheumatoid Arthritis: A Hospital Based Study
}

\author{
Authors \\ Kumar Rajesh ${ }^{1}$, Pradhan $R N^{2}$, Bhagatula $S^{3}$ \\ ${ }^{1}$ Consultant Medicine, Bokaro General Hospital (DNB teaching hospital) \\ ${ }^{2}$ Department of Medicine, HOD, Bokaro General Hospital (DNB teaching hospital) \\ ${ }^{3}$ DNB Resident, Department of Medicine, Bokaro General Hospital (DNB teaching hospital) \\ Email: ${ }^{1}$ drrajeshdr@yahoo.co.in, ${ }^{2}$ rabindranath.dr@gmail.com, ${ }^{3}$ stumpy278276@gmail.com \\ Corresponding Author \\ Kumar Rajesh \\ Consultant Medicine, Bokaro General Hospital (DNB teaching hospital)
}

\begin{abstract}
Extra articular manifestations of rheumatoid arthritis are seen in 10-20\% of individuals representing the systemic nature of the disease.20-30\% of these, suffer with neuropathic manifestations .It contributes significantly to the disability caused by the disease warranting to pick up those sub clinical cases of neuropathy and to treat them early. Paucity of literature on rheumatoid neuropathy creates a lacuna in critical evaluation and discussion of this subject..

Aim of The Study: It was to find incidence of peripheral neuropathy and their patterns in patients of rheumatoid arthritis and its correlation with severity of the disease and markers of inflammation

Materials And Methods: A cross sectional randomised observational study was conducted in patients diagnosed of rheumatoid arthritis (based on EULAR, ACR2010 criteria) between May 2011-2013 were questioned pertaining to symptoms of neuropathy with special attention to distal symmetric sensory involvement. All individuals were subjected to complete electrophysiological nerve conduction study. Disease severity was assessed with DAS28 scoring system and were tested for inflammatory markers (ESR, CRP, Anti CCP antibodies).

Results: A total of 50 cases of rheumatoid arthritis were analysed and incidence of neuropathy was found in 60\%(30/50) with predominantly pure sensory neuropathy 50\%(15/30,) sensory motor neuropathy 30\% (9/30), mono neuritis multiplex10\%(3/30) and carpal tunnel syndrome 10\%(3/30). Incidence was found to be more in female sex as is the disease itself and is associated with a DAS 28 score of $>5.1$ in $96.67 \%$, a positive CRP in $86.6 \%$, ESR of $30-60 \mathrm{~mm} / \mathrm{hr}$ in $60 \%$ and a strongly positive anti-CCP>60 IU in $66.6 \%$ individuals.

Conclusion: Peripheral neuropathy in rheumatoid arthritis is relatively a common manifestation with female preponderance and fifty percent of patients having sub clinical neuropathy. Majority have pure sensory type with a mean duration of 55.04 months of illness, severe form of disease and positive inflammatory markers.
\end{abstract}

Key Words: DAS 28, Extra-Articular manifestation, Peripheral Neuropathy, Rheumatoid Arthritis

Abbreviations: Anti CCP- anti -cyclic citrullinated polypeptides , VAS- Visual analog scale, HAQ Health associated questionnaire, ESR- erythrocyte sedimentation rate , CRP - C Reactive protein ,DAS28 disease activity score in28joints, 


\section{INTRODUCTION}

Rheumatoid arthritis (RA) is a chronic inflammatory disease characterised primarily by an erosive symmetric polyarthritis. Apart from involving the synovium of the joints, it can also involve virtually any system in the body ranging from lungs to brain ${ }^{1}$. RA affects about $0.8 \%$ of general population. Extraarticular manifestations of RA are seen in $10-20 \%$ of total patients ${ }^{2}$. The neurological manifestations in rheumatoid arthritis include atlantoaxial subluxation, polymyositis, mono neuritis multiplex, peripheral neuropathy, rheumatoid nodules in central or peripheral nervous system, rheumatoid vasculitis causing stroke and or neuropathy and rarely amyloidosis ${ }^{3}$.Although a number of studies have described peripheral neuropathy in RA, the incidence has not been worked out, which may be due to small sample size and its wide variation in various series. In an Indian study by Kar et $\mathrm{al}^{4}$ the overall prevalence of neuropathy was $20 \%$ with the overt manifestations in $5.75 \%$ of patients. In a series by Nadkar etal ${ }^{5} 30 \%$ RA patients had neuropathy of which five each were overt and sub clinical respectively and one patient had entrapment neuropathy. It is often difficult to diagnose these early neuropathies clinically due to symptoms resulting from pain in the joints and limitation of movement. However by means of electroneuromyography, it is possible to show objectively the existence and distribution of even subclinical neuropathies ${ }^{6}$.

The reported frequency of neurological involvement in RA patients depends on definitions used, diagnostic methods, studied populations .In recent years it is being recognised as an important extra articular manifestation of RA and research contributes significantly to the disability caused by the disease ${ }^{7}$. Hence a cross sectional randomised observational study was undertaken to determine the frequency and patterns of peripheral neuropathies and their correlation with severity of disease and markers of inflammation in rheumatoid arthritis in a tertiary care hospital.

\section{MATERIALS AND METHODS}

\section{Source of data}

Patients presented with complaints of pain and stiffness in small joints of hands and feet in the Rheumatology outpatient department, diagnosed RA on the basis of ACR/EULAR 2010 criteria $^{8}$ were selected randomly according to the inclusion criteria laid during the period May 2011 to May 2013.

\section{Sample size}

50 cases of diagnosed RA patients

\section{Study design}

Two years of cross sectional, randomized, observational study.

\section{Inclusion criteria}

Diagnosed cases of rheumatoid arthritis irrespective of their neurological status.

\section{Exclusion criteria}

Other causes of neuropathy such as Diabetes Mellitus, Vitamin B12, Folate deficiency, Leprosy, common drugs causing neuropathy, alcoholism, occupational exposure to heavy metals and other connective tissue disorders like Lupus and S Jogren's were excluded.

\section{Methodology}

Each patient was questioned about symptoms of neuropathy and areas or limbs involved with special attention to distal symmetric sensor motor involvement. The duration of the disease was inquired and confirmed with reports. A full neurological examination including cranial nerves was performed. Estimation of Rheumatoid factor, anti CCP titre (quantitative), ESR, CRP (qualitative) and $\mathrm{X}$ rays of small joints of hand were done. A tender joint count and a swollen joint count were done to find out DAS28, a VAS scoring of pain on a scale of 0 to 10 was also done, HAQ in Indian context as per A. Kumar and A.N. Malaviya et $\mathrm{al}^{9}$ with a disability score ranging from 0 to 36 and index of maximum 3 
was done. A complete electro physiological Nerve Conduction Study (NCS) using Medelee Sapphire Premire (015W008C machine from Recorder And Medicare Systems) was done.

\section{Statistical methods}

Data were processed in excel sheet and analysed using SPSS software. Quantitative variables were summarized using mean and standard deviation while categorical variables were tabulated using frequencies and percentage. Student $\mathrm{T}$ - test was used for testing significance of differences between the mean values of two continuous variables. Probability $(\mathrm{P})$ level of $<0.05$ was considered significant. Regression analysis was used to find relation between variables like age, VAS score, HAQ status and DAS28 with neuropathy.

\section{OBSERVATION AND RESULTS}

50 patients of diagnosed Rheumatoid arthritis were evaluated for peripheral neuropathies from May 2011 to May 2013.Out of50 patients,35 were female and 15 were male. The mean age of incidence of RA was 48.67 in males and 47.91in females (Table 1). A positive but non-significant relationship $\left(r^{2}=0.299\right)$ was noted in respect to age and causation of peripheral neuropathy. The incidence of peripheral neuropathies in RA were $60 \%$. There was significant difference in incidence of neuropathies in both sexes. It was $71.4 \%$ in females and33.3\% in males. Of all the types of neuropathies, pure sensory was the most common type $(50 \%)$ and was $80 \%$ among females. Others are sensorimotor in $30 \%$, mono neuritis multiplex and carpal tunnel syndrome each in $10 \%$ but no significant difference in distribution of neuropathy in both sexes $\mathrm{p}=0.373$ (Fig. $1 \& 3$ )

Disease activity score 28 was severe $(>5.1)$ in majority of patients found to be $96.67 \%$ associated with neuropathy and a significant association and positive correlation was found with it $(\mathrm{p}<0.0001)$. Majority of patients had raised CRP while negative CRP was noted in only 8 patients. A strong association was observed between $\mathrm{CRP}$ and peripheral neuropathy. $\mathrm{P}$ value<0.05)

Table no.1:- Base line characteristics of the study group of patients showing all the variables and the respective data

\begin{tabular}{|l|l|l|l|}
\hline $\begin{array}{l}\text { Sl. } \\
\text { No. }\end{array}$ & Baseline characteristics & $\begin{array}{l}\text { Total group }(\mathrm{n} \\
=50)\end{array}$ & Median \\
\hline 01 & Male : Female & $15: 35$ & - \\
\hline 02 & $\begin{array}{l}\text { Age of diagnosis } \\
\text { (mean } \pm \text { SD) }\end{array}$ & $\begin{array}{l}48.14 \pm 11.79 \\
\text { (years })\end{array}$ & 51 \\
\hline 03 & Duration of disease & $\begin{array}{l}55.04 \pm 27.80 \\
(\text { month })\end{array}$ & 59 \\
\hline 04 & TJC ( mean \pm SD $)$ & $13.54 \pm 6.14$ & 14 \\
\hline 05 & SJC $($ mean \pm SD $)$ & $4.42 \pm 3.36$ & 4 \\
\hline 06 & RF Positivity & $92 \%(\mathrm{n}=46)$ & - \\
\hline 07 & DAS $-28($ mean \pm SD $)$ & $5.87 \pm 1.05$ & 6.025 \\
\hline 08 & HAQ( mean \pm SD $)$ & $1.97 \pm 1.21$ & 1.75 \\
\hline 09 & VAS( mean \pm SD $)$ & $45 \pm 20.03$ & 40 \\
\hline 10 & ESR( mean \pm SD $)$ & $58.48 \pm 30.82$ & 57.5 \\
\hline 11 & Erosive disease & $96 \%(\mathrm{n}=48)$ & - \\
\hline
\end{tabular}

Table no.2:- Clinical characteristics of patients with and without peripheral neuropathy

\begin{tabular}{|c|c|c|c|c|}
\hline \multirow[t]{2}{*}{ Objective } & $\begin{array}{l}\text { With } \\
\text { peripheral } \\
\text { neuropathy }\end{array}$ & $\begin{array}{l}\text { Without } \\
\text { peripheral } \\
\text { neuropathy }\end{array}$ & \multirow[t]{2}{*}{$\begin{array}{l}\mathrm{T}_{\text {cal }} \\
\text { (t'test) }\end{array}$} & \multirow[t]{2}{*}{ p- value } \\
\hline & $\begin{array}{lrl}\mu & \pm \\
(\mathrm{n}=30)\end{array}$ & $\begin{array}{lrl}\mu & \pm \\
(\mathrm{n}=20)\end{array} \quad \delta_{\mathrm{x}}$ & & \\
\hline $\begin{array}{l}\text { Mean } \\
\text { duration in } \\
\text { months }\end{array}$ & $\begin{array}{l}60.23 \quad \pm \\
23.28\end{array}$ & $\begin{array}{l}47.25 \\
32.55\end{array}$ & 1.54 & $P>0.05$ \\
\hline $\begin{array}{l}\text { Duration } \\
60 \text { months }\end{array}$ & $\begin{array}{ll}72.41 & \pm \\
12.85 & \end{array}$ & $\begin{array}{ll}86.17 & \pm \\
28.05 & \end{array}$ & 2.05 & $\mathrm{P}<0.05$ \\
\hline $\begin{array}{l}\text { Male } \\
\text { Female }\end{array}$ & $5 / 15: 25 / 35$ & $\begin{array}{l}10 / 15 \\
10 / 35\end{array}$ & & $\mathrm{P}<0.01$ \\
\hline RF positivity & 28 & 18 & & $\mathrm{P}<0.01$ \\
\hline DAS 28 & $6.53 \pm 0.54$ & $4.88 \pm 0.83$ & 7.86 & $\mathrm{P}<0.05$ \\
\hline $\begin{array}{l}\text { Joint space } \\
\text { erosions } \\
\text { (Hand } \mathrm{X} \text { - } \\
\text { ray) }\end{array}$ & 29 & 19 & & $\mathrm{P}<0.01$ \\
\hline TJC & $\begin{array}{ll}16.23 \quad \pm \\
5.39 & \end{array}$ & $9.5 \pm 4.94$ & 4.55 & $\mathrm{P}<0.05$ \\
\hline SJC & $5.8 \pm 3.49$ & $2.35 \pm 1.76$ & 4.61 & $\mathrm{P}<0.05$ \\
\hline HAQ & $\begin{array}{ll}2.35 & \pm \\
1.098 & \\
\end{array}$ & $1.403 \pm 1.16$ & 2.88 & $P<0.05$ \\
\hline VAS & $53 \pm 19.15$ & $33 \pm 14.90$ & 4.14 & $\mathrm{P}<0.05$ \\
\hline ESR & $\begin{array}{ll}71.83 & \pm \\
29.61 & \\
\end{array}$ & $\begin{array}{ll}38.45 & \pm \\
20.19 & \end{array}$ & 4.74 & $\mathrm{P}<0.05$ \\
\hline
\end{tabular}




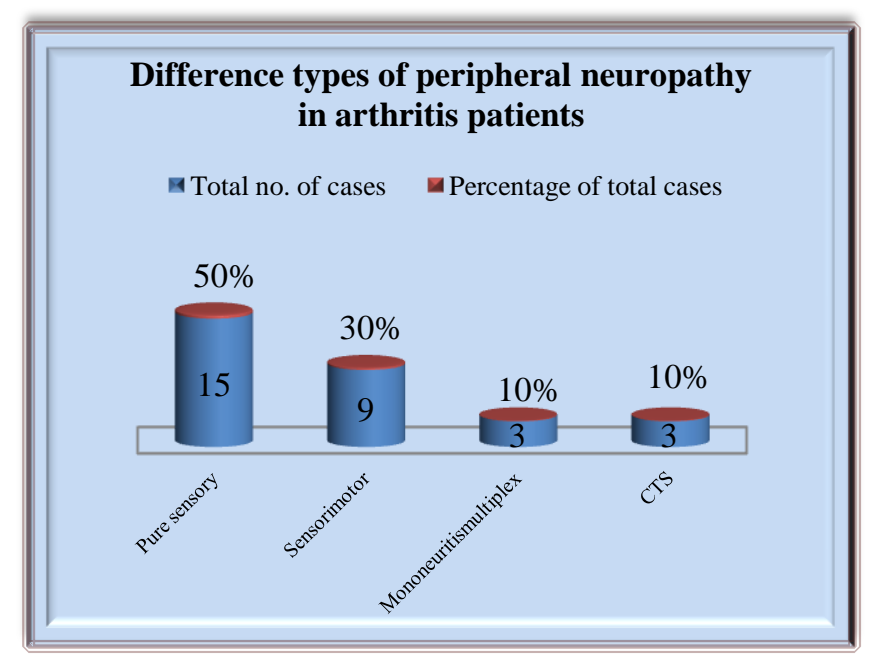

Fig 1: Difference types of peripheral neuropathy in arthritis patients.

(CTS - carpal tunnel syndrome)

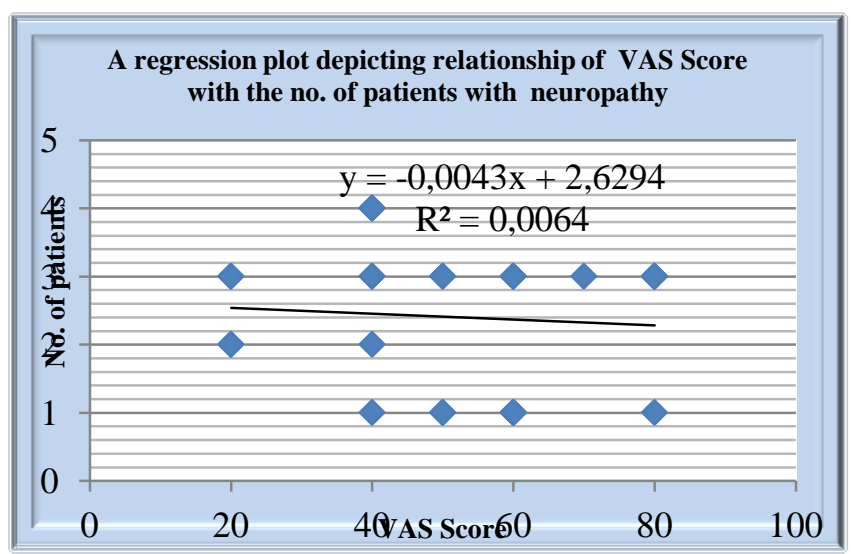

Fig 2: VAS scores among the patients of study, very poor correlation have been found applying VAS scores inR ${ }^{2} 0.006$ patients with peripheral neuropathy.

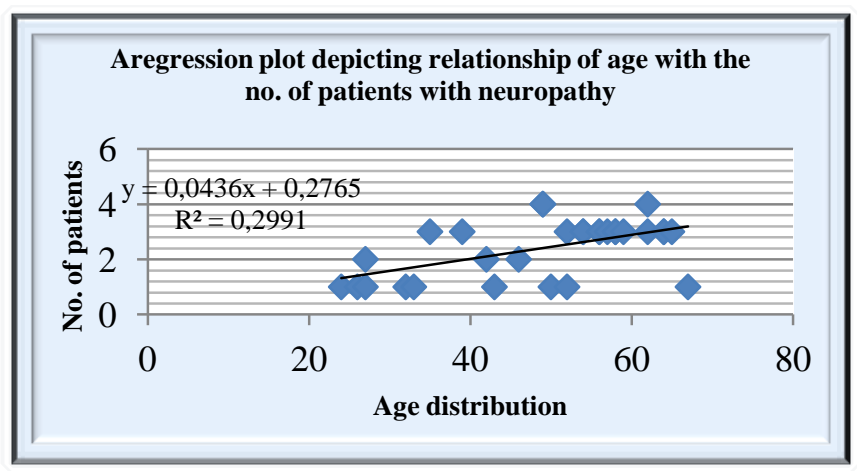

Fig 3: Showing a regression plot depicting relationship of age with the number of patients having neuropathy. The regression plot is positively correlated which denotes that age at presentation is a predictor for the causation of neuropathy.

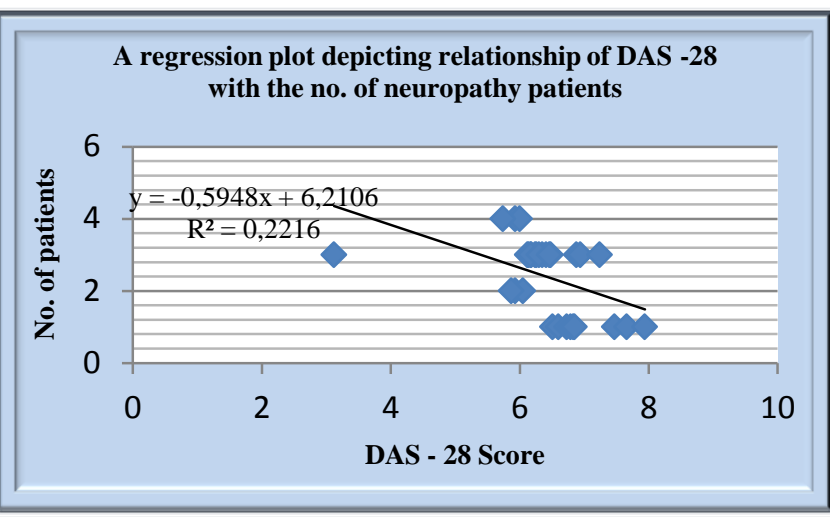

Fig 4: Showing a regression plot depicting relationship of DAS 28 Score with the number of patients having neuropathy. Here the regression plot clearly shows that DAS 28 is a positive measure of RA.

More than $45 \%$ females had their ESR exceeding $60 \mathrm{~mm} / \mathrm{hr}$ and similar number of patients showed ESR to be between $30-60 \mathrm{~mm} / \mathrm{hr}$. While ESR of males fell mostly between $30-60 \mathrm{~mm} / \mathrm{hr}$. Around $33.33 \%$ of males revealed their ESR to be $<30 \mathrm{~mm} / \mathrm{hr}$. The difference was found to be highly significant. (P value <0.01)

More than $65 \%$ of cases with peripheral neuropathy were noted to be having Anti CCP $>60$ IU. Whereas half of the patients without peripheral neuropathy revealed very high ELISA values (>60\%). A few (13.33\%) patients with peripheral neuropathy showed Anti CCP to be between 40-59 IU. While a significant number of cases $(35 \%)$ without peripheral neuropathy were found to behaving moderately high Anti CCP antibodies. Only $16.67 \%$ of patient \& merely $10 \%$ of cases were found to be negative. The association of Anti CCP with the causation of peripheral neuropathy has been found to be highly significant ( $\mathrm{P}$ value was0.002).

Only 2 patients had no active bony erosive changes of rheumatoid arthritis rest all 48 patients had some evidence of erosive changes. 29 patients had evidence of peripheral neuropathy associated with erosive joint involvement.

Distribution of TJC Score among the patients In the study group it was observed that high number of females and males had a tender joint count (TJC) between 10 and 20. Relatively less number 
of patients having extensive involvement with TJC of over 20 joints were encountered. The Questionnaire addressed to patients showed VAS ranging from 0 to 5 . It was revealed that scores were mostly between $0 \& 3$.

\section{DISCUSSION}

Rheumatoid arthritis is a multisystem autoimmune disorder, characterized by chronic deforming arthritis and a significant number of patients reveal involvement of nervous system in the form of peripheral neuropathy. Many of these patients are asymptomatic and neuropathy is determined only by meticulous physical examination as well as detailed nerve conduction studies. The incidence of RA increases between 25-55 years, after which plateaus until the age of 75 and then decreases. In our present study patients were divided in to five groups with a mean age of 48.67 in males and 47.91 in females. Majority of our patients were between the age group of 50-60, $5(33.7 \%)$ males and $14(40 \%)$ females which is at par with study by C.T.Paese et al. We found subclinical neuropathy in all the subjects $50(100 \%)$ included where as Agarwal et $\mathrm{al}^{10}$ found 46 out of 108 patients, Lanzillo et $\mathrm{al}^{11}$ found 26 out of 40 patients and none of the patients by Bharadwaj et al. had subclinical neuropathy.

Our present study which was conducted over 2 years revealed a pure sensory neuropathy being the most common type $(50 \%)$ of which majority were females(80\%), Monodeep Biswas et al ${ }^{12}$ also found pure sensory form as predominant type in their study(51.7\%). Study by Agarwal et al showed sensory neuropathy in $(25.95 \%)$ which is at variance with ours reason seeming to be a larger number of subjects $(n=108)$ in their study. Lanzillo et al in their study of 40 patients found mixed sensorimotor neuropathy $(63.41 \%)$ as predominant type which was around $30 \%$ in our study which were similar to that of Agarwal et al (23.14\%) and Monodeep Biswas et al (22.1\%). Electrophysiological evidence of neuropathy is found in 60\% (30/50) of patients which was far greater compared to Aneja et $\mathrm{al}^{13}(37.87 \%)$ and on par with Dani et $\mathrm{al}^{14}(50 \%)$.

The ratio of male to female patients with neuropathy was (1:5.7) which was much higher than other study groups(1:1.4). No statistical significance was found between two attributes i.e. sex and presence of neuropathy, where as Albani et al found male gender to be significantly related to peripheral neuropathy $(p<0.04)$, where as Sirvi et $\mathrm{al}^{6}$, Bhardwaj et al and Lang et al found no gender correlations as our study. Positive but non significant correlation between age and neuropathy ( $r^{2}$ value0.299) had been found in agreement with Agarwal et al, Bharadwaj et al, Hamsed sa et al. In consonance with Albani et al, RA positivity was significantly found to be associated with neuropathy $(\mathrm{p}<0.01)$, DAS28 of $>5.1$ is strongly associated (96.67\%) with NCS evidence of neuropathy which was significantly correlated $(p<0.0001)$ to neuropathy consistent with studies conducted by Bayrak et $\mathrm{al}^{15}$. We found significant association of neuropathy with all markers of inflammation (ESR,CRP,RA factor, anti $\mathrm{CCP}$ ) in contrast to $\mathrm{Sim} \mathrm{MK}^{16}$ et al who found a significant association with only a high anti CCP values .

\section{CONCLUSIONS}

Being a chronic and multisystemic disease, meticulous nerve conduction studies and histopathological analysis of various nerves is warranted to diagnose peripheral neural involvement. In our present study fifty percent of patients had subclinical neuropathy with female predominance and a mean duration of 55.04and 27.80 months respectively, as standard deviate suggesting its chronicity. Predominant variety was pure sensory in agreement with certain studies and at variance with others, emphasizing need for further studies. Positive association with RA factor positivity and DAS28 score of >5.1and albeit weak but positive correlation with age of patients and significant association with raised ESR, CRP \& anti CCP was found. These variable results are probably due to limited number of 
patients emphasizing the essentiality of nerve biopsy in confirming the diagnosis.

\section{REFERENCES}

1. O'Dell JR : Rheumatic disease. In Goldman L, Ansiello D, editors : Cecilmedicine $-23: 2007$

2. Lipsky PE : Rheumatoid arthritis. In Fauci AS, Kasper DL, Longo DL, editors:Harrisons Principles of Internal Medicine, ed. 17: 2008

3. QJM : An International Journal of Medicine;Vol.99, Issue 2, ): 69- 79.

4. Kar M, Mukherjee S, Mandal D, et al. Neuropathy in rheumatoid arthritis: clinicaland electrophysiological observations. Bull Indian Rheumatism Assoc 1991; 5: 80-2.

5. Nadkar MY, Agarwal R, Samant RS, Chhugani SJ, Idgunji SS, Iyer $\mathrm{S}$, et al. Neuropathy in rheumatoid arthritis. J Assoc Physicians India.2001;49:217-20.

6. Sivri A, Güler-Uysal F. The electroneurophysiological findings in rheumatoidarthritis patients. Electromyogr Clin Neurophysiol. 1999 Oct-Dec; 39(7) :387-91.

7. Singh H, Handa R , Sood S, Kumar H, Goyal M, Kumar S. To study the frequency of subclinical neuropathy in RA and its relation to duration of disease. JAPI.org,December 2009, 57. (special issue).

8. Aletaha D, Neogi T, Silman AJ, Funovits $\mathrm{J}$, Felson DT, Bingham CO, 3rd, et al. 2010 Rheumatoid arthritis classification criteria: an American College of Rheumatology/European League Against Rheumatism collaborative initiative. Arthritis Rheum.2010;62:2569-81.

9. Malaviya AN, Singh RR, Kapoor SK, Sharma A, Kumar A, Singh YN. Prevalence of rheumatic diseases in India: results of a population study. $J$ Ind RhellmaJismAssoc 1994; 2: 13-7.
10. Agarwal V, Singh R, Wiclaf, Chauhan S, Tahlan A, Ahuja CK, et al. A clinical, electrophysiological, and pathological study of neuropathy in rheumatoid arthritis. Clin Rheumatol. 2008;27:84144.

11. Lanzillo B, Pappone N, Crisci C, di Girolamo C, Massini R, Caruso G. Subclinical peripheral nerve involvement in patients with rheumatoid arthritis. Arthritis Rheum. 1998;41:119602.

12. Biswas M, Chatterjee A, Ghosh SK et al. Prevalence, types, clinical associations and determinants of peripheral neuropathy in rheumatoid patients. Ann Indian Acad Neurol 2011;14:194-7

13. Aneja R, Singh MB, Shankar S, Dhir V, Grover R, Gupta R, et al.Prevalence of peripheral neuropathy in patients with newly detectedrheumatoid arthritis. Indian J Rheumatol 2007 ; 2 : 47-50

14. Dani K, Ramachandran R, Capell HA, Madhok $\mathrm{R}$ et al. Neuropathies in therheumatoid patients : A case of the heavy hand. Scott Med J 2005, 50 : 125-6

15. Bayrak AO, Durmus D, Durmaz Y et al. Electrophysiological assessment of polyneuropathic involvement in rheumatoid arthritis: relationships among demographic, clinical and laboratory findings. Neurol Res 2010; 32:711-14

16. Sim MK, Kim D-Y, Yoon J, Park DH, Kim Y-G. Assessment of Peripheral Neuropathy in Patients With Rheumatoid Arthritis Who Complain of Neurologic Symptoms. Annals of Rehabilitation Medicine. 2014;38(2):249-55. 